\title{
Argentina: de la breve experiencia de centroderecha al regreso del Peronismo
}

\section{Argentina: From the brief center-right experience to the return of Peronism}

\section{Nicolás Liendo}

Universidad Sergio Arboleda

nicolas.liendo@usa.edu.co

\section{Camilo González iD}

Universidad Sergio Arboleda

manuelc.gonzalez@usa.edu.co

\section{Resumen}

Este artículo analiza los factores que condujeron a la victoria del Peronismo en las elecciones generales de 2019. A través de un análisis descriptivo argumentamos que el contexto económico previo a la elección y la cohesión partidaria fueron los factores que permitieron que el Peronismo recuperará la presidencia y la mayoría en el Congreso. De esta manera, los malos resultados económicos del presidente Macri en el año previo a la elección debilitaron sus posibilidades de reelección, lo que le permitió al Peronismo una oportunidad de construir una coalición electoralmente competitiva en la que convergieron sectores kirchneristas y no kirchneristas. El reto del nuevo gobierno peronista es la recuperación económica en un contexto de volatilidad y de potenciales conflictos dentro de la coalición de gobierno.

Palabras clave: Argentina, Cambiemos, Peronismo, gobernabilidad, elecciones.

\section{Abstract}

This article analyzes the factors that led to the victory of Peronism in 2019 general elections. We conduct a descriptive analysis arguing that the economic prior context and party cohesion were the determinant factors that allowed Peronism to regain the presidency and legislative majority. In this way, the poor economic results of President Macri in the year before the election weakened his chances for reelection, giving Peronism an opportunity to build an electorally competitive coalition in which Kirchner and non-Kirchner sectors converged. The challenge for the new Peronist government is economic recovery in a context of volatility and potential conflicts within the government coalition.

Keywords: Argentina, Cambiemos, Peronism, governance, elections.

Articulo: Recibido el 26 de mayo de 2020 y aprobado el 26 de junio de 2020.

\section{Cómo citar este artículo:}

Liendo, N. \& González, C. (2020). Argentina: de la breve experiencia de centroderecha al regreso del Peronismo. Reflexión política 22(45), pp. 16-29. doi: https://doi.org/10.29375/01240781.3917 


\section{Introducción}

En diciembre de 2015, Mauricio Macri se convirtió en el primer presidente de Argentina identificado abiertamente con la centroderecha y no con los partidos tradicionales nacionales como el peronista Partido Justicialista (PJ) y la Unión Cívica Radical (UCR). Bajo una plataforma política de apertura económica como solución a los problemas económicos estructurales, Macri gobernó Argentina enfrentando las contradicciones de su propia coalición política (Cambiemos) frente a la aplicación de las reformas económicas y un desfavorable ambiente internacional que terminaron por agudizar la crisis económica del país suramericano. Para finales de 2019, la economía, lejos de recuperarse, volvió a la espiral de la crisis, lo que le permitiría al Peronismo volver al poder tras un proceso de reunificación interna y programática sobre la base de la vieja receta de lograr mayor justicia social a partir de una mayor intervención estatal para paliar la precaria situación económica.

El regreso del Peronismo al poder estuvo determinado por el desempeño económico del país durante la administración Macri (2015-2019), y la consecuente cohesión interna de las distintas facciones peronistas, tejida por Cristina Kirchner. Ante el fracaso de la estrategia gradualista de las reformas económicas de Macri, el Peronismo se cohesionó en torno a una candidatura que generaba menos resistencia a un electorado no-kirchnerista, pero proponiendo una plataforma más identificada con las políticas más radicales de las administraciones de Cristina Kirchner (2007-2015). Sin embargo, vale resaltar que el resultado de la pugna entre gradualistas y pro-shock en el gobierno de Cambiemos afectó el desempeño que tuvieron las reformas económicas. La tendencia más gradualista se impuso, y generó que el gobierno privilegiará los acuerdos políticos sobre el ajuste. Esto causó resultados positivos a corto plazo, pero se postergaron las soluciones de problemas estructurales, los cuales acabarian desbordando al gobierno tras la inesperada alza de las tasas de interés en Estados Unidos. En pocas palabras, las elecciones generales en Argentina denotaron la importancia del desempeño económico en las decisiones electorales, unido a la vigencia del Peronismo como opción política hegemónica.

El artículo está organizado de la siguiente manera. La primera sección describe el ascenso de Cambiemos al gobierno y las características de su programa político. A su vez, explica la pugna al interior de la coalición de gobierno, sus efectos en la gobernabilidad y en el desempeño económico de la administración Macri (2015-2019). La segunda sección se dedica a explicar el proceso de cohesión partidaria que experimentó el Peronismo, que resultó en la candidatura presidencial de Alberto Fernández - Cristina Kirchner. La tercera sección se enfoca en la descripción de los resultados electorales a nivel presidencial, legislativo, así como las explicaciones desde la literatura académica de las claves del triunfo peronista: la cohesión partidaria y el voto retrospectivo. Posteriormente, enumeramos los desafíos que enfrentará la administración Fernández en los campos de la economía y la gobernabilidad. Finalmente, concluimos con la exposición de los cambios en el sistema político argentino en términos de un proceso de transición del bipartidismo al bipolarismo durante el periodo 2015-2019.

\section{Las contradicciones del gobierno de Cambiemos}

Mauricio Macri tuvo un largo camino antes de llegar a la presidencia de la República. Nació en el seno de una de las familias de la élite empresarial argentina. Sin embargo, en el país del sur, la pasión por el fútbol y la política están íntimamente relacionadas, y, de ese modo, Macri saltó a la fama nacional por llevar la etapa más exitosa en la historia de Boca Juniors, el club más popular del país. Después, participó en la creación de un partido político de derecha (Compromiso por el Cambio) y, como miembro de este, compitió por la Alcaldía de Buenos Aires en 2003; sin embargo, perdió en el ballotage. En el 2007, ganaría la elección y sería reelecto en 2011 por mayoría abrumadora. Su gestión en Buenos Aires coincidió con la hegemonía de los Kirchner en la Argentina, quienes controlaban casi todas las gobernaciones con 
mayoría amplia en el Congreso, pero Macri practicó una crítica mesurada al ejecutivo nacional. Al final, Macri terminó con altos índices de aprobación por su gestión y amplió las fronteras de su (nuevo) partido Propuesta Republicana (PRO), lo cual lo llevó a competir en otras provincias.

El camino de la candidatura de Macri se empezó a pavimentar con la construcción de una coalición más amplia a su partido PRO, cuando incluyó a Elisa Carrió y al centenario partido Radical (UCR). La decisión en la convención de Gualeguaychú de la UCR de acompañar a Macri fue crucial, pues este partido, si bien supo ser el mayor contrincante del Peronismo, sufrió un colapso parcial y perdió importancia a nivel nacional, aunque se las ha ingeniado para conservar presencia a nivel subnacional. De esta forma, Macri resolvió su escasa presencia territorial con el aparato tradicional de la UCR, más la figura mediática de Elisa Carrió.

Así, Cambiemos ${ }^{1}$ llegó a las Primarias Abiertas Simultáneas y Obligatorias (PASO) ${ }^{2}$ de agosto de 2015, donde obtuvo la segunda votación más alta $(30,11 \%)$ detrás del Frente Para la Victoria $(38,67 \%)$, liderado por Daniel Scioli, lo que abrió la posibilidad de una candidatura competitiva desde la centroderecha. Otro resultado importante de la jornada, lo constituyó la coalición disidente del Peronismo, Una Nueva Alternativa (UNA), donde Sergio Massa logró 14,33\% de la votación de las primarias (Alles, Jones, y Tchintian, 2016). Esa última votación evidenció la fractura al interior del Peronismo en un clivaje kirchnerista y nokirchnerista, que sería clave en las elecciones presidenciales de ese año.

Durante la primera vuelta, en octubre de 2015, las preferencias electorales se mantuvieron inalterables: Scioli logró 37.08\% de los votos, seguido de Macri (34,15\%) y de Massa (21,39\%). Los resultados demostraron que el voto hacia el Peronismo kirchnerista se había estancado en favor de las opciones de centroderecha de Cambiemos y peronista no kirchnerista de UNA. Finalmente, tras 12 años de hegemonía peronista kirchnerista (2003-2015), el candidato de Cambiemos logró la presidencia de Argentina, venciendo en la segunda vuelta al candidato del FPV con el 51,34\% de los votos (Alles et al., 2016, p. 2).
La victoria de Cambiemos ha sido interpretada en análisis que privilegian el contexto preelectoral y la geografía electoral (Alles et al., 2016; Murillo, Rubio, \& Mangonnet, 2016). La primera interpretación otorga importancia al grave deterioro económico del país. Después de 2011 se habría apagado el "viento de cola" que, a través del boom de las commodities, permitió a los gobiernos tener excesiva liquidez por vía de las importaciones de soja. Tras la caída del precio de la soja y el sostenimiento de un gasto público desmedido, el déficit fiscal fue aumentando sustancialmente $\mathrm{y}$, a pesar de las crecientes restricciones al libre comercio, la inflación también se disparó en los dos últimos años del segundo mandato de Cristina Fernández de Kirchner (2011-2015). El otro factor dañino para las aspiraciones de continuidad del Kirchnerismo se encontraba en las numerosas investigaciones que surgian por actos de corrupción que implicaban a altos funcionarios en el gobierno (vicepresidente, ministros, etc.). Esto motivó un voto influenciado por la identidad negativa (Medeiros y Noël, 2014; Meléndez, 2019) hacia la presidenta, que afectó la imagen del candidato oficialista durante las elecciones. Por otro lado, Macri logró victorias amplias a nivel subnacional en las provincias con mayor dinamismo económico (Alles et al., 2016), e incluso en aquellas electoralmente determinantes como Santa Fe, Córdoba, Mendoza, Ciudad Autónoma de Buenos Aires (CABA) y Buenos Aires (Murillo et al., 2016, p. 42).

Sin embargo, a nivel legislativo, la nueva coalición de gobierno no logró equiparar sus resultados con los conseguidos a nivel presidencial. De los 130 escaños en juego en la Cámara de Diputados, Cambiemos logró solo 47, y en el Senado 9 de 24 (Alles et al., 2016). En total, la configuración del nuevo parlamento argentino dibujó un escenario de gobierno con minoría legislativa donde el partido de gobierno, Propuesta Republicana (PRO), se ubicó como la tercera fuerza legislativa con 41 diputados de 257 y 4 de 72 senadores (Murillo et al., 2016). Este escenario condicionaría las acciones políticas de la administración Macri y tendrían repercusiones en la implementación de sus reformas económicas. El programa económico de Mauricio Macri se fundamentó en tres grandes objetivos: la apertura

${ }^{1}$ Cambiemos es una coalición de partidos y movimientos políticos que reúne a la Propuesta Republicana (PRO), a la Coalición Cívica (CC) y la Unión Cívica Radical (UCR) y que surgió en 2015 con el objetivo de construir una lista unitaria para vencer en las PASO'(Murillo et al., 2016).

${ }^{2}$ Las primarias Abiertas Simultáneas y Obligatorias surgieron tras la Reforma Constitucional de 2009, que buscaba consolidar el sistema de partidos mediante la reducción de la oferta partidaria. De esta manera, las coaliciones políticas que buscaban presentarse en las elecciones generales deben superar el umbral del $1,5 \%$ de los votos emitidos (Gallo, 2016). 
económica, la promoción de las inversiones privadas y la reducción de la intervención del Estado en la vida económica (Vommaro y Gené, 2017). Así, a principios del 2016, el gobierno acudió al levantamiento de la tasa de cambio y a la negociación de los "fondos buitres" para permitir el ingreso de divisas con el objetivo de mejorar el stock de dólares en el mercado argentino, manteniendo el precio de la divisa bajo. En sintonía con esta primera medida, el gobierno de Mauricio Macri avanzó en la eliminación de impuestos y restricciones a las exportaciones de trigo y carne, de este modo, favoreció al sector exportador, uno de los principales actores dentro de la coalición del nuevo gobierno (Freytes y Niedzwiecki, 2018).

Por otro lado, gracias a la negociación y posterior aprobación de una ley para permitir el endeudamiento, Argentina obtuvo un crédito por 12.500 millones de dólares para sufragar los gastos corrientes del Estado. Así mismo, el Banco Central acumuló reservas que trazarían una hoja de ruta para efectuar un proceso de focalización inflacionaria que ubicaría la inflación en 17\% para finales de 2017 (Alcalá Kovalski, 2019).

Sin embargo, la aplicación de la reducción de los subsidios a los servicios públicos (agua, gas y electricidad), con el fin de aumentar la inversión privada en el sector energético, reveló la pugna interna dentro de la coalición de gobierno. El debate entre los ortodoxos y los gradualistas se enfocó en la velocidad de implementación de las reformas; para los primeros era indispensable aplicar una rápida apertura de las protecciones aduaneras, reducción de la inversión pública y de los salarios con el fin de reducir la demanda a corto plazo, mientras que los segundos abogaban por una actuación más progresiva del gobierno en materia económica, donde se tuviera en cuenta los consenso sociales y políticos para legitimar el ajuste (Vommaro y Gené, 2017, p. 236). La resistencia de la clase media al aumento de las tarifas debilitó a la facción ortodoxa, e impuso la posición más gradualista del ajuste. Como consecuencia, el gobierno se dedicó a negociar sus políticas económicas con sectores peronistas no kirchneristas y con los gobernadores de las provincias con el ánimo de lograr apoyos parlamentarios y compromisos en la implementación territorial, respectivamente
(Anria y Vommaro, 2020; Freytes y Niedzwiecki, 2018). Este giro se concibió en la medida de aplicar los ajustes económicos "administrando los tiempos para evitar chocar de frente con un bloque social hostil” (Rosso, 2019, p. 9) movilizado, principalmente, por el Peronismo. Partiendo de ese supuesto, el gobierno de Macri accedió a negociar algunos puntos de su agenda económica, teniendo presente la reciente división interna y el histórico poder territorial preservado por el peronismo.

El primer resultado de la negociación con el bloque peronista no kirchnerista fue la continuidad de la mayoría de la política social de las administraciones Kirchner, e incluso su expansión en términos de cobertura (Llanos y Maia, 2019; Natanson, 2019). La expansión del programa Asignación Universal por Hijo (AUH $)^{3}$ se dio gracias al cambio de criterio de elegibilidad que pasó a cubrir a menores de edad que no habían participado en el programa anteriormente $\mathrm{y}$, a su vez, a familias con padres trabajadores independientes que contribuyeran en el régimen impositivo simplificado (Niedzwiecki y Pribble, 2017). Por otro lado, Macri accedió a la creación de un nuevo sistema pensional denominado Pensión Universal para la Vejez para adultos mayores de 65 años, así, benefició a cerca del 80\% de los pensionados que no podían contribuir al sistema (2017, p. 84). La implementación de estas medidas estuvo orientada a lograr una mayor aprobación política de la gestión presidencial por parte de los principales afectados por las medidas de ajuste económico, tanto desmovilizando a los sectores populares informales históricamente receptores de los programas sociales, como obteniendo una mayor adhesión de las clases medias preocupadas por sus ingresos pensionales. Al mismo tiempo, se buscaba consolidar uno de los principales grupos etarios que apoyaron su candidatura presidencial.

Posteriormente, los réditos políticos del giro hacia el gradualismo se verían reflejados en las elecciones legislativas de medio término de octubre de 2017, en la cual se renovaron 127 de 215 escaños de diputados, y 24 de 72 en el Senado (Llanos \& Maia, 2019). Cambiemos logró aumentar su presencia en el Congreso, pasó de 86 diputados a 107, y de 15 senadores a 24 (Freytes y Niedzwiecki, 2018, p. 147). En el campo peronista, el bloque

${ }^{3}$ La Asignación Universal por Hijo (AUH) es un programa de transferencia condicionada, creado durante la primera administración de Cristina Fernández (2007-2011). El programa beneficia a niños cuyos padres hacen parte del mercado laboral informal o se encuentran desempleados mediante una asignación monetaria mensual. 
kirchnerista redujo su presencia a 67 diputados y 10 senadores, mientras que la facción no kirchnerista, aunque aumentó su número de diputados a 40, disminuyó su número de senadores a 23. Bajo esta nueva configuración de bloques legislativos signada por la división del Peronismo, el gobierno se dispuso a profundizar las reformas económicas que, debido a la minoría legislativa, se había visto obligada a reformular, a costa de obtener mayor legitimidad política para implementarlas.

Ciertamente, el triunfo electoral en las legislativas dio impulso al gobierno para aprobar e implementar las reformas pensional y laboral. En primer lugar, la implementación de la reforma pensional implicó un acuerdo previo alrededor un nuevo Pacto Fiscal entre el gobierno central y los gobernadores provinciales (Freytes y Niedzwiecki, 2018). En la negociación, el gobierno central se comprometía al cambio del impuesto a las ganancias que era recaudado e invertido en el Fondo Conurbano Bonaerense y en la Administración Nacional de la Seguridad Social (ANSES), a fin de hacerlo coparticipable con las provincias. A cambio, los gobernadores renunciarían a los juicios contra la Nación por la liquidación a las cajas previsionales y aplicarían una política de reducción de impuestos provinciales, incluso de recorte del gasto público. Con ello, la administración Macri "liberaría recursos para que el tesoro afrontara las transferencias acordadas sin comprometer adicionalmente la meta fiscal" (Freytes y Niedzwiecki, 2018, p. 148) para concitar apoyos provinciales a la futura reforma.

Adicionalmente, la reforma previsional presentada por el gobierno, se propuso la actualización de los haberes jubilatorios que pasaron a ser ajustados por el salario y la recaudación tributaria. Además, para el aumento de la edad de jubilación se planteó una modalidad optativa (65 años para las mujeres y 70 para los hombres), unida a un incentivo para las empresas con el fin de no hacer aportes en dichos periodos (Freytes \& Niedzwiecki, 2018). Sin embargo, el punto que empezó a generar malestar fue el ajuste de la fórmula para calcular las jubilaciones. Aunque la fórmula servía a los propósitos del gobierno para sanear el déficit fiscal del sistema previsional, afectaba sensiblemente el aumento que recibirían los jubilados. Desde entonces, los sindicatos argentinos y agrupaciones de izquierda tomaron las calles para protestar contra la medida (Rosso, 2019), aunque la reforma pensional logró ser aprobada gracias a las alianzas políticas creadas tras el Pacto Fiscal con los gobernadores, actores clave en la politica argentina.

En paralelo, el gobierno impulsó la reforma laboral con el objetivo de reducir los costos de despido, y así, facilitó la tercerización (Freytes \& Niedzwiecki, 2018). Esta reforma empoderaba a las empresas y afectaba a los trabajadores, incluidos los sindicatos con medidas como la reforma de la Ley de Contrato de Trabajo (LCT) y la reducción de indemnizaciones. La fuerte resistencia de los sindicatos le obligó a postergar indefinidamente la reforma laboral, lo que evidenció la poca capacidad del presidente pora impulsar su agenda de reformas económicas (Rosso, 2019).

Pronto los ecos de los reveses en el frente doméstico fueron magnificados por dos inesperados giros a nivel internacional. Tanto la crisis turca, como el alza de las tasas de interés por parte de la Reserva Federal de los Estados Unidos en 2018, pulverizaron uno de los principales pilares de la política económica del gobierno Macri: el acceso a los mercados internacionales. Tras este revés internacional, el gobierno pidió un rescate al Fondo Monetario Internacional (FMI), con el objetivo de mantener a flote la economía argentina (Llanos y Maia, 2019). De esta manera, las condiciones del ente financiero multilateral obligaban a Macri a dar un paso al costado en su política gradualista, e imponer un plan económico extremadamente ortodoxo: políticas de austeridad fiscal que implicaban el recorte del gasto público, la reintroducción de las tasas de exportación (Alcalá Kovalski, 2019) y las restricciones en las tasas de cambio (Murillo \& Zarazaga, 2020). De esta manera, la escasez de capital obligó al gobierno argentino a replantear las políticas distributivas en base a las recomendaciones de los entes multilaterales de crédito, lo que movió el enfoque más hacia la derecha del espectro ideológico (Murillo, Oliveros, y Vaishnav, 2011)

El año electoral de 2019 inició con un balance negativo para la política económica de Macri: la pobreza se ubicó cerca del 35\%, el desempleo fue del 10\% y la inflación se duplicó al 50\% anual (Rosso, 2019); así, la economía argentina se ubicaba entre las tres de peor desempeño en América Latina junto a Venezuela y Nicaragua (Murillo y Zarazaga, 2020). Macri aceptó las condiciones del FMI, y así “comenzó a perder su capacidad para mantener las expectativas y el apoyo de los sectores sociales que 
había sido importantes para su ascenso, incluyendo grandes segmentos de la clase media" (Anria y Vommaro, 2020, p. 8), y abrió una oportunidad para la reconstrucción del Peronismo de cara a las elecciones del 2019.

\section{Cerrando la grieta peronista}

Paralelamente a la debacle económica que sufría la administración Macri, el Peronismo iniciaba un proceso de reunificación de sus distintas facciones, siendo conscientes que la división del Peronismo había favorecido el ascenso de Macri cuatro años antes. Para ello, la líder de la facción Peronista Kirchnerista, la expresidenta Cristina Fernández de Kirchner, trazó una estrategia para unificar a un Peronismo fracturado. Dicha estrategia fue proponer una fórmula presidencial integrada por Alberto Fernández como candidato presidencial y ella como su vicepresidenta (Murillo y Zarazaga, 2020). Alberto Fernández, quien había sido jefe de gabinete de la administración Néstor Kirchner (2003-2008), fue muy crítico de la respuesta del gobierno de Cristina (2008-2011) frente al paro de los agricultores contra el impuesto a la soja. Esto supuso una de las primeras escisiones internas en el Peronismo entre los que adherían al segundo gobierno de los Kirchner y aquellos que lo rechazaban (Mauro, 2011). Lo anterior tendría repercusión en la contienda electoral del 2015, donde quedó evidenciado una regularidad en la política argentina: la división del Peronismo hace improbable su regreso o continuidad en el gobierno (Calvo y Murillo, 2012; Murillo, 2017).

En ese sentido, la candidatura FernándezFernández-Kirchner fue una apuesta política para superar las divisiones del Peronismo. En primer lugar, la superación de los clivajes sociales que dividen su representación entre los intereses de sectores obreros y aquellos informales. Zarazaga (2018) ha calificado la grieta del Peronismo como una "grieta social" debido a la heterogeneidad que atraviesa al Peronismo. Este autor precisa que, si bien el Peronismo originario tuvo como su electorado base a los obreros sindicalizados a partir de las décadas de 1990 y 2000, los trabajadores informales y desempleados empezaron a competir con el sindicalismo la representatividad al interior del Peronismo. Esto se debió a la adaptabilidad del
Peronismo (Burgess y Levistky, 2003) en acoger medidas para representar a estos sectores mediante la implementación de programas de trasferencias condicionadas, particularmente desde el segundo gobierno Kirchner (2008-2011) que ampliamente fueron favorecidos por el boom de las materias primas (Murillo, 2017; Zarazaga, 2018).

Por otro lado, la candidatura fue una estrategia oportuna para atraer votantes no kirchneristas. Al no liderar la fórmula presidencial se redujo la resistencia interna de varias facciones peronistas que no favorecían el liderazgo de la expresidenta y pasó desapercibida su gran imagen negativa para los no partidarios ${ }^{4}$. De la misma forma, el electorado fuera del Peronismo vio en la candidatura de Alberto Fernández una figura identificada con la moderación política que podía imponerse sobre el radicalismo del ala kirchnerista del Peronismo.

Al sanar estas divisiones, el Peronismo caminó hacia las elecciones de octubre de 2019 cohesionado en torno a una candidatura que expresaba la reconciliación de los distintos clivajes peronistas. Además del trabajo de cohesión interno, la coalición peronista se fortaleció a partir de las "denuncias del antiperonismo que ayudan a definir dicha identidad" (Murillo et al., 2016, p. 206). En efecto, la campaña de reelección de Macri se centró en explotar la división peronismo/ antiperonismo (Ostiguy, 1997), hizo alusión a los escándalos de corrupción en los que involucraban a la ex presidenta y, a su vez, exaltó los valores del republicanismo en contraposición al populismo kirchnerista (Murillo y Zarazaga, 2020).

En cambio, el Peronismo supo conectar durante la campaña con uno de los principales problemas de los argentinos: la situación económica. Según la encuesta Latinobarómetro del 2018, año preelectoral, las principales preocupaciones se centraron en los problemas económicos (29,9\%), la desocupación (15\%) y la situación política $(11,8 \%)$. Claramente, el Peronismo explotó los resultados negativos de la administración Macri, y para ello propuso la reversión de varias reformas impopulares que surgieron tras la pérdida de financiamiento internacional. En contraste, la campaña del gobierno, ausente de logros económicos que presentar, se dirigió al electorado apelando a las

${ }^{4}$ Cinco meses antes de las PASO, la encuestadora Query presentó sus resultados sobre la imagen positiva y negativa de los candidatos. La expresidenta Fernández de Kirchner obtuvo una imagen positiva del $37 \%$ y negativa del $54 \%$, solo superado por el presidente Macri quien obtuvo una imagen negativa del $57 \%$. 
políticas de "mano dura" contra la criminalidad, las desventajas de los programas de transferencias condicionadas y la oposición al aborto (Murillo y Zarazaga, 2020, p. 130).

\section{Resultados electorales}

El punto de partida del regreso del Peronismo al gobierno fue la celebración de las primarias abiertas de agosto de 2019. Las PASO, más que confirmar la oferta política para las elecciones generales de octubre, demostraron ser una radiografía del refortalecimiento del Peronismo y de la desaprobación al gobierno. Contra todos los pronósticos de las encuestas que anunciaban cierta paridad, pero con ventaja para la oposición, la lista Frente de Todos conformada por el Peronismo unificado obtuvo el $49,4 \%$ de los votos frente al $32,9 \%$ de la lista oficialista Juntos Por el Cambio (Ver Tabla 1). Dentro de esta primera contienda electoral, otras listas lograron su participación en las elecciones generales como Consenso Federal $(8,4 \%)$, Frente de Izquierda y de los Trabajadores - Unidad $(2,9 \%)$, Frente Nos $(2,7 \%)$ y Unite por la Libertad y la Dignidad $(2,2 \%)$.

Tabla 1. Comparación de los resultados PASO y elecciones presidenciales 2019

\begin{tabular}{|c|c|c|c|}
\hline Lista & $\begin{array}{c}\text { Votación } \\
\text { PASO }\end{array}$ & Candidatos & $\begin{array}{c}\text { Votación } \\
\text { presidencial }\end{array}$ \\
\hline $\begin{array}{l}\text { Frente de } \\
\text { Todos }\end{array}$ & $49,4 \%$ & $\begin{array}{l}\text { Alberto } \\
\text { Fernández }\end{array}$ & $48,1 \%$ \\
\hline $\begin{array}{l}\text { Juntos por } \\
\text { el Cambio }\end{array}$ & $32,9 \%$ & $\begin{array}{c}\text { Mauricio } \\
\text { Macri }\end{array}$ & $40,3 \%$ \\
\hline $\begin{array}{c}\text { Consenso } \\
\text { Federal }\end{array}$ & $8,4 \%$ & $\begin{array}{l}\text { Roberto } \\
\text { Lavagna }\end{array}$ & $6,1 \%$ \\
\hline $\begin{array}{c}\text { FIT } \\
\text { Unidad }\end{array}$ & $2,9 \%$ & $\begin{array}{c}\text { Nicolás Del } \\
\text { Caño }\end{array}$ & $2,1 \%$ \\
\hline Frente Nos & $2,7 \%$ & $\begin{array}{c}\text { Juan Gómez } \\
\text { Centurión }\end{array}$ & $1,7 \%$ \\
\hline $\begin{array}{c}\text { Unite por } \\
\text { la Libertad } \\
\text { y la } \\
\text { Dignidad }\end{array}$ & $2,2 \%$ & José Espert & $1,4 \%$ \\
\hline
\end{tabular}

Fuente: Elaboración propia con datos presentados por La Nación (2019b).
Los resultados de la primera vuelta reeditaron los resultados de las PASO. El candidato peronista, Alberto Fernández, logró ganar la presidencia, venció al candidato-presidente Mauricio Macri tras lograr el 48,1\% de los votos ${ }^{5}$. Geográficamente, la mayor votación del peronismo se concentró en sus bastiones tradicionales de las provincias menos desarrolladas del noroeste como Santiago del Estero $(74,8 \%)$, Formosa $(65,1 \%)$, Chaco $(55,7 \%)$ y Catamarca $(56,6 \%)$. Por el contrario, Macri obtuvo amplias victorias en las provincias con mayores ingresos como Córdoba (61,3\%), Mendoza (50\%) y Santa Fe (43,5\%). En este sentido, es necesario anotar que, tanto Fernández como Macri, concentraron el $88 \%$ de los votos válidos, lo que nos lleva a pensar que Argentina ha transitado del tradicional bipartidismo del siglo $\mathrm{XX}$ a un bipolarismo caracterizado por una fuerte división entre peronistas y antiperonistas.

Por otro lado, las elecciones legislativas permitieron al Peronismo kirchnerista recuperar el control de ambas cámaras parlamentarias que había perdido en las elecciones de medio término de 2017. Como se expone en las Tablas 2 y 3, el peronismo kirchnerista aumentó su presencia tanto en la Cámara de Diputados como en el Senado. En la primera cámara legislativa, el Peronismo kirchnerista pasó de 107 diputados a 120, sin lograr la mayoría requerida para tener quorum propio. Caso contrario sucedió en el Senado donde el peronismo kirchnerista pasó de 24 a 37 senadores, de este modo logró el número suficiente para aprobar sin negociación su agenda legislativa. Aunque Cambiemos sufrió un notable retroceso, este no fue tan significativo. A nivel presidencial, la coalición del gobierno logró aumentar la votación obtenida en las PASO en casi 8 puntos y, a nivel parlamentario, aumentó su presencia en ambas cámaras legislativas, a pesar de estar en uno de los contextos económicos más negativos de la historia argentina.

\section{Claves del triunfo peronista}

¿Qué explica el regreso del Peronismo al poder? Una primera aproximación es entender las elecciones generales de 2019 en términos de voto castigo a la administración de Macri, en relación con el contexto económico inmediato a la elección. En este sentido,

\footnotetext{
${ }^{5}$ Argentina tiene un sistema de elección presidencial de umbral reducido. La normativa prevé que el candidato ganador de la elección presidencial debe obtener al menos el $40 \%$ de los votos o lograr una diferencia de 10 puntos sobre el segundo candidato en contienda.
} 
Tabla 2. Comparación Cámara de Diputados 2016 y 2019

\begin{tabular}{|c|c|c|c|c|c|c|}
\hline Bloque & $\begin{array}{c}\text { Votación } \\
2017\end{array}$ & $\begin{array}{c}\text { Total curules } \\
2017\end{array}$ & Bloque & Votación 2019 & Curules 2019 & $\begin{array}{c}\text { Total curules } \\
2019\end{array}$ \\
\hline Cambiemos & $41,7 \%$ & 107 & $\begin{array}{c}\text { Peronismo } \\
\text { Kirchnerista }\end{array}$ & $46,6 \%$ & 68 & 120 \\
\hline $\begin{array}{l}\text { Peronismo } \\
\text { Kirchnerista }\end{array}$ & $20,8 \%$ & 67 & Cambiemos & $40,3 \%$ & 56 & 119 \\
\hline $\begin{array}{c}\text { Peronismo } \\
\text { No } \\
\text { Kirchnerista }\end{array}$ & $16,2 \%$ & 40 & $\begin{array}{c}\text { Peronismo } \\
\text { No } \\
\text { Kirchnerista }\end{array}$ & $7,3 \%$ & 1 & 5 \\
\hline $\begin{array}{c}\text { 1País } \\
\text { (Massimo) }\end{array}$ & $5,8 \%$ & 21 & $\begin{array}{l}\text { Consenso } \\
\text { Federal }\end{array}$ & $3,2 \%$ & 3 & 4 \\
\hline Izquierda & $4,3 \%$ & 4 & Izquierda & $2,8 \%$ & 0 & 2 \\
\hline Otros & $8,4 \%$ & 19 & Otros & 0,61 & 2 & 7 \\
\hline
\end{tabular}

Fuente: Elaboración propia con datos presentados por Vommaro y Gené (2017); Freytes y Niedzwiecki (2018) y La Nación (2019a).

Tabla 3. Comparación Senado 2017 y 2019

\begin{tabular}{ccccccc} 
Bloque & $\begin{array}{c}\text { Votación } \\
\mathbf{2 0 1 7}\end{array}$ & Total Curules & Bloque & Votación 2019 & Curules 2019 & $\begin{array}{c}\text { Total Curules } \\
\mathbf{2 0 1 9}\end{array}$ \\
\hline Cambiemos & $41 \%$ & $\mathbf{2 4}$ & $\begin{array}{c}\text { Peronismo } \\
\text { Kirchnerista }\end{array}$ & $46,3 \%$ & 15 & $\mathbf{3 7}$ \\
\hline $\begin{array}{c}\text { Peronismo } \\
\text { Kirchnerista }\end{array}$ & $31,9 \%$ & $\mathbf{1 0}$ & Cambiemos & $41,9 \%$ & 8 & $\mathbf{2 9}$ \\
\hline $\begin{array}{c}\text { Peronismo } \\
\text { No }\end{array}$ & $18,6 \%$ & $\mathbf{2 3}$ & $\begin{array}{c}\text { Consenso } \\
\text { Federal }\end{array}$ & $5,82 \%$ & 0 & $\mathbf{1}$ \\
\hline $\begin{array}{c}\text { Kirchnerista } \\
\text { Otros }\end{array}$ & $7,8 \%$ & $\mathbf{1 5}$ & Otros & $3,5 \%$ & 1 & $\mathbf{3}$
\end{tabular}

Fuente: Elaboración propia con datos presentados por Vommaro y Gené (2017); Freytes y Niedzwiecki (2018) y La Nación (2019a).

se ha argumentado que el ciclo electoral afecta la naturaleza del voto económico. Singer y Carlin (2013) han demostrado que las consideraciones económicas prospectivas suelen tener importancia al inicio del mandato presidencial, pero conforme se extiende en el tiempo, los votantes se inclinan a votar usando sus consideraciones retrospectivas.

Lo anterior tiene sentido si comparamos los resultados de las elecciones 2017 y 2019 a partir del desempeño económico previo. Para las elecciones de medio término en 2017, Cambiemos logró la mayoría legislativa gracias a la implementación gradualista de sus reformas económicas que logró mantener el apoyo de sectores de clase media y contuvo el descontento de los sectores informales. Sin embargo, las elecciones de 2019 significaron la derrota de la coalición de gobierno tras la crisis del financiamiento externo y la implementación de políticas de austeridad a partir 2018. Esto resintió la opinión pública frente al manejo económico del gobierno que terminó por reducir la gestión económica de Macri a "un experimento gubernamental que agravió demasiado a los abajo y no terminó de conformar a los de arriba” (Rosso, 2019, p. 5).

Bajo la misma perspectiva, Ratto (2020) ha demostrado que la economía no dejó de ser una predictora de los resultados en estas elecciones. Esta demuestra, a partir de datos de la encuesta Latin American Public Opinion Project (LAPOP) a inicios del 2019, que una de las principales características de los votantes que favorecieron al Peronismo fue la valoración negativa de la economía, lo que aumentaba un 39\% las posibilidades de votar contra la candidatura de Macri, unida a no identificarse partidariamente con Cambiemos. 
Sin embargo, los problemas económicos son apenas una condición necesaria para entender la derrota de Macri. Los factores políticos complementan el análisis al resaltar que la división de la centroderecha argentina y las características del Peronismo determinaron la movilización de los votantes. Por un lado, la coalición Cambiemos debió competir con coaliciones dentro de su mismo espacio ideológico como Frente de Nos y Unite por la Libertad y la Dignidad (Ratto, 2020, p. 39), lo que le resto votantes frente a una coalición peronista cohesionada.

Sin embargo, sigue siendo evidente la centralidad del Peronismo dentro del sistema político argentino. La candidatura única del Peronismo demostró la resiliencia de este ante los desafíos que encaró en 2015 y 2017, fue particularmente relevante su adaptabilidad política y la activación de su heterogénea base social. Sobre la evolución organizacional del Peronismo, Levitsky (2001) ha argumentado que este actor político ha sido flexible a la hora de adaptarse a nuevos contextos electorales y mantenerse vigente en el sistema de partidos argentinos. De este modo, el peronismo ha sobrevivido al declive de los partidos de masas obreras en la última mitad del siglo XX, a base de una combinación de enraizamiento social y liderazgo autónomo.

Inmerso en un contexto de reformas económicas, el Peronismo inició un proceso de des-obrerización de su electorado mediante la incorporación de nuevos actores como los sectores informales, proceso que se cristalizaría durante los gobiernos Kirchner (2003-2015). Esta convergencia heterogénea, no exenta de tensiones, se impulsó mediante la oferta de políticas públicas diferenciales (Zarazaga, 2018) que, por un lado, beneficiaba a los obreros con recomposiciones de sus salarios y a los trabajadores informales mediante un amplio programa de transferencias condicionadas.

En ese mismo escenario, el liderazgo del Peronismo se descentralizó, se hizo más fluido, y permitió mayor rotación en el liderazgo. Así mismo, la renovación en liderazgo permite que las actuaciones de los nuevos liderazgos sean más discrecionales y apunten a estrategias adaptativas. Así, la inexistencia de cuerpos directivos en el Peronismo ha hecho que los liderazgos sean más personalistas (Levitsky, 2001), siendo reflejo de esas dinámicas las existencias facciones peronistas, cuya identidad responde o adversa liderazgos a nivel nacional, así como el amplio margen de maniobra con las que han contado los candidatos peronistas para establecer alianzas a nivel nacional y provincial.

Durante las elecciones del 2019, el peronismo apeló a ambas estrategias organizacionales. La activación de la identidad peronista, tanto en los sectores formales como informales, demuestra que el voto peronista es de pertenencia, como afirma Torres (2017), aunque en algunos casos dicha pertenencia se haya fortalecido gracias a los programas implementados por los gobiernos peronistas (Murillo, 2017). No obstante, es preciso anotar que la política distributiva del Peronismo se ha articulado en base a redes clientelares que distribuyen servicios básicos (comida, medicinas etc.) en los distritos electorales más pobres. Estas redes permiten el control del voto mediante el seguimiento de las preferencias de los votantes, e incluso disciplinando la disidencia electoral (Brusco, Nazareno, y Stokes, 2004). Por otro lado, Auyero (2000) precisa que, a pesar de ser una estrategia utilitaria, la práctica clientelar peronista contiene un fuerte componente afectivo que refuerza la identidad partidaria entre los electores de estos distritos. Para las elecciones de 2019, el grueso de votantes que eligieron la candidatura Fernández-Fernández de Kirchner era de estrato socioeconómico bajo y trabajadores formales que, en 2015, había votado al candidato peronista no kirchnerista, Sergio Massa (Murillo y Zarazaga, 2020).

Sin embargo, una prueba patente de este enraizamiento social profundo es que este actor político es una fuente constante de representación política, ya que "es el único movimiento político que cuenta con presencia en todas las arenas de la vida social: tiene organizaciones en los barrios, tiene bancadas en el congreso, tiene agrupaciones universitarias, tiene sindicatos, tiene organizaciones de jóvenes" (Casullo, 2015, p. 5). Son estas distintas organizaciones y sus respectivas tareas de movilización política en las que, según Zarazaga (2014), la credibilidad de los punteros (brokers) peronistas ha generado un mayor compromiso por parte de los votantes en términos de una mayor expectativa de recibir beneficios.

Sin embargo, el catalizador de esa unidad peronista fue la renovación en el liderazgo. Aunque el Peronismo es catalogado como un movimiento político descentralizado (Casullo, 2015; Levitsky 
y Roberts, 2011), la disciplina del voto se logró gracias a la reconciliación entre el bloque peronista kirchnerista y aquello que lo adversa en torno a una candidatura única. Ciertamente, una candidatura resistida como la de las elecciones de 2015 influyó. El paso al costado dado por la expresidenta al postularse como candidata a la vicepresidencia permitió que el control de la campaña fuera asumido por Alberto Fernández, imprimió una sensación de renovación en la coalición peronista, sin perder el apoyo de la facción kirchnerista.

En conclusión, el regreso del Peronismo se dio gracias a la combinación de factores políticos que atañen a la adaptabilidad del Peronismo como movimiento político, y a la oportunidad brindada por un mal contexto económico que erosionó el apoyo a la candidatura de Macri y permitió la proliferación de varias coaliciones de centroderecha que dispersaron el voto en el campo oficialista. Esto demuestra que la economía sigue siendo el factor determinante a la hora de votar, y que el Peronismo continua siendo un actor hegemónico en la política del país austral, independiente de si es gobierno $u$ oposición.

\section{Desafios del nuevo gobierno peronista}

En un contexto de alta volatilidad, el regreso del Peronismo a la Casa Rosada no vislumbra un gobierno con estabilidad como lo fueron las anteriores administraciones peronistas entre 2003 y 2015, aupadas por el auge de los precios de la commodities. Así, el recurrente problema estructural de la economía, como los conflictos al interior de la coalición de gobierno, serán los principales retos que el presidente Alberto Fernández deberá sortear a lo largo de su mandato. Su capacidad para mantener esta gobernabilidad en la macroeconomía y la macropolítica, tendrá correlato en la más ardua tarea de sostener la gobernabilidad de la calle, donde frecuentemente los argentinos se manifiestan en cantidades ante conflictos sociales. Hasta el momento, a pesar de la profunda crisis, aunque en la región hay cierta estabilidad macroeconómica y política, pero con altos niveles de conflictividad en las calles, en Argentina se observa bajos niveles relativos de conflictividad en las calles y serias dificultades macroeconómicas y políticas en el corto plazo.
Como su antecesor, Fernández deberá hacer frente a la agudización de la crisis económica tras el cierre del acceso al financiamiento externo. Para el politólogo Andrés Malamud, el nuevo presidente peronista "enfrentará dos grandes desafíos: la crisis económica y la impaciencia popular" (Guarino, 2019). Anticipándose a la conjunción de estos factores, en diciembre de 2019 logró la aprobación de la Ley de Emergencia Económica en un intento por encaminar la política monetaria y fiscal, y en la que se cuentan medidas de corte social como el congelamiento de las tarifas de servicios públicos por seis meses y la congelación de los ajustes pensionales en un intento por atajar un temprano rebrote de la insatisfacción social.

Sin embargo, el pago de la deuda resulta ser la tarea más importante, ya que es un eje transversal de la recurrente crisis económica del país austral. El gobierno de Fernández ha mantenido su promesa de renegociar la deuda con los tenedores de bonos, cuya negociación debería haber culminado en marzo (Matera, 2020), sin embargo, la pandemia de la COVID-19 la ha retrasado. Sobre esto último, el gobierno argentino fue uno de los primeros en aplicar medidas de aislamiento obligatorio junto a Perú y Colombia para contener la expansión del virus, lo que mantuvo una tasa de mortalidad relativamente baja $^{6}$. A pesar de los esfuerzos del gobierno por contenerla, la pandemia ha generado estragos en la economía, ya que para abril del 2020 se registró una caída interanual del Producto Interno Bruto (PIB) de aproximadamente 26,4\%, cifra que amenaza con estancar la economía del país austral a niveles incluso inferiores a las registradas tras la crisis del 2001(El País, 2020).

Por otro lado, la tensión en el frente económico también tiene repercusiones al interior de la coalición de gobierno. Fernández deberá hacer frente a los gobernadores peronistas y a su poderosa vicepresidenta, Cristina Fernández de Kirchner. En cuanto a los primeros, deberá alcanzar un acuerdo sobre las asignaciones fiscales para las provincias, y frente a la segunda, deberá recortar su influencia en la toma de decisiones, a pesar de que su capital político, tanto en su nominación, como en su elección como presidente fue relevante. A primera vista, existe un balance de poder entre ambos, en donde predomina los nombramientos

${ }^{6}$ Según datos del Coronavirus Resource Center, al 25 de mayo de 2020, Argentina registra 12.076 casos de contagios y 456 fallecidos (The John Hopkins University, 2020). 
presidenciales en los ministerios de Economía, Relaciones Internacionales y jefe del Banco Central, mientras que los ministerios de Defensa, Interior y Cultura han sido cuotas de la vicepresidenta. No obstante, dependerá de la habilidad política del presidente para liderar al país en tiempos de crisis, que la figura de su vicepresidenta no se reivindique, presentándose como una amenaza a su autoridad y la estabilidad del sistema democrático.

\section{Conclusiones}

Las elecciones del 2019 mantuvieron un escenario político-electoral signado por la importancia del desempeño de la economía, pero con la novedad de que el sistema político ha logrado introducir un mayor grado de competitividad a través de la polarización que el Peronismo y Cambiemos han protagonizado desde las elecciones de 2015. Los resultados electorales y su contexto económico previo dejaron claro la importancia de las preocupaciones económicas en las decisiones electorales de los argentinos. Cada vez más el voto retrospectivo sigue siendo una variable ineludible en los estudios electorales argentinos, se destaca que el contexto económico es primordial a la hora de analizar no solo las elecciones, sino las acciones de gobierno. De esta manera, podemos entender cómo Macri logró ganar las legislativas de medio término de 2017 gracias a un giro gradualista en sus reformas promercado que coincidieron con su único año de crecimiento económico positivo, pero fracasar en su intento de reelección en 2019 ante la crisis del financiamiento internacional que irremediablemente tuvo que atajar con politicas más ortodoxas.

A nivel de los actores políticos, el Peronismo sigue conservando la hegemonía en el sistema político, lo que quedó demostrado con el triunfo en las elecciones del año pasado. Como movimiento político, la clave de su supervivencia partidaria ha sido la ampliación y la segmentación de su electorado unido a la cohesión de sus facciones, lo que nos sugiere que un Peronismo unificado es suficiente para lograr una victoria electoral, e incluso para mantener la estabilidad en el gobierno. No obstante, el ciclo económico es diametralmente opuesto al de las pasadas administraciones peronistas, por lo que la recurrente crisis económica pondrá a prueba la cooperación entre las distintas facciones, y la supervivencia del nuevo gobierno peronista.
En contraste, la centroderecha finalmente articuló una propuesta política en Argentina bajo el referente electoral de Cambiemos. A pesar de la derrotay desu mal evaluadagestión, la centroderecha argentina se logró afianzar como una opción política competitiva para un grupo significativo de votantes. La irrupción de Cambiemos representa un hito en la historia de la representación política en Argentina, que el reconocido politólogo Aníbal Pérez Liñán destaca toda vez "que es el sector de derecha democrático -que históricamente nunca estuvo bien representado- haya encontrado un espacio de representación" (Pikielny, 2019). Los triunfos en las presidenciales de 2015 y las legislativas de 2017 demostraron la capacidad de atracción electoral de la centroderecha, pero también de negociación y alianza con otros sectores para alcanzar metas electorales y de gobierno.

En suma, a nivel del sistema político, podríamos argumentar que estamos arribando al final del bipartidismo entre peronistas y radicales, para iniciar un escenario de bipolarismo caracterizado por un sistema político polarizado y con alternancia entre los polos ideológicos. Este bipolarismo es la reemergencia de una vieja división argentina entre peronistas y antiperonistas, que en el siglo $\mathrm{XX}$ se intentó zanjar por vías antidemocráticas (por ejemplo, golpes militares y proscripción). Sin embargo, con el regreso a la democracia, las administraciones Kirchner (20032015) y la aparición de Cambiemos ha adoptado un matiz más electoral, incluso conservando algunas líneas sociales y etnográficas enunciadas por Ostiguy (1997). Tras la alternancia política vivida entre 2015 y 2019, la nueva polarización que se ha incrustado en el centro de la política argentina representa un avance en la consolidación de la democracia que, particularmente, en lo electoral ha significado que, si bien regresó el Peronismo, también significó la reemergencia competitiva del antiperonismo.

\section{Referencias}

Alcalá, M. (2019). Lessons learned from the Argentine economy under Macri. Recuperado 28 de abril de 2020, de https://www.brookings.edu/blog/upfront/2019/09/05/lessons-learned-from-the-argentineeconomy-under-macri/

Alles, S., Jones, M. P. y Tchintian, C. (2016). The 2015 Argentine presidential and legislative elections. 
Electoral Studies, 100(43), 184-187. DOI: https://doi.org/10.1016/j.electstud.2016.05.001

Anria, S. y Vommaro, G. (2020). En Argentina, un "giro a la derecha" que no fue y el improbable regreso del peronismo de centro-izquierda. Más poder local, (40), 6-10.

Auyero, J. (2000). The logic of clientelism in Argentina: An ethnographic account. Latin American research review, 55-81.

Brusco, V., Nazareno, M. y Stokes, S. C. (2004). Vote buying in Argentina. Latin American Research Review, 6688. DOI: https://doi.org/10.1016/j.electstud.2016.05.001

Burgess, K.y Levistky, S. (2003). Explaining Populist Party Adaptation in Latin America: Environmental and Organizational Determinants of Party Change in Argentina, México, Perú, and Venezuela. Comparative Political Studies, 36(8), 881-911. DOI: https://doi.org/10.1177/0010414003256112

Calvo, E. y Murillo, M. V. (2012). Argentina: The persistence of peronism. Journal of Democracy, 23(2), 148161. DOI: https://doi.org/10.1353/jod.2012.0029

Casullo, M. E. (2015). Argentina: del bipartidismo a la democracia peronista. Nueva sociedad, 257, 16-28.

Corporación Latinobarómetro. (2018). Latinobarómetro 2018 - Argentina. Recuperado 1 de mayo de 2020, de http://www.latinobarometro.org/latOnline.jsp

El País. (2020). La economía argentina se derrumba 26,4 $\%$ en abril; supera peor registro de la crisis de 2001. Recuperado 30 de junio de 2020, de https://negocios.elpais.com.uy/noticias/economiaargentina-derrumba-abril-supera-peor-registro-crisis. $\underline{\mathrm{html}}$

Freytes, C. y Niedzwiecki, S. (2018). Argentina 2017: la dinámica intertemporal de la reestructuración económica. Revista de ciencia política (Santiago), 38(2), 125-154. DOI: https://doi.org/10.4067/s0718090x2018000200125

Gallo, A. (2016). A PASO desdoblado. Análisis sobre la aplicación conjunta del sistema de PASO (primarias abiertas simultáneas y obligatorias) y eldesdoblamiento delas elecciones subnacionales en la Argentina. Reflexión Política, 18(36), 80100. DOI: https://doi.org/10.29375/01240781.2654

Guarino, L. (2019). Andrés Malamud: "Si Fernández no estabiliza la economía, el escenario será de renuncia o kirchnerización”. Forbes Argentina. Recuperado de https://www.forbesargentina. com/10518-2/

La Nación. (2019a). Elecciones 2019. El Nuevo Congreso. Recuperado de https://www.lanacion.com.ar/politica/ elecciones-2019-bancas-tiempo-real-quienes-entran$\underline{\text { nid2300186 }}$

La Nación. (2019b). Elecciones 2019. Presidente. Recuperado de https://www.lanacion.com.ar/politica/mapa-resultados- elecciones-generales-2019-nid2300184\#/presidente

Levitsky, S. (2001). Organization and labor-based party adaptation: The transformation of Argentine Peronism in comparative perspective. World Politics, 54(1), 27-56. DOI: https://doi. org/10.29375/01240781.2654

Levitsky, S., \& Roberts, K. M. (2011). The resurgence of the Latin American left. JHU Press.

Llanos, M. y Maia, J. (2019). Argentina 2019: Broken Economy, Strengthened Democracy. Hamburg: GIGA Focus Lateinamerika.

Matera, M. (2020). The Alberto Fernández Administration at Two Months. Recuperado 25 de mayo de 2020, de https://www.csis.org/analysis/alberto-fernándezadministration-two-months

Mauro, S. (2011). Transformaciones en la política argentina. La conformación del peronismo no kirchnerista como coalición partidaria nacional (2005-2009). Revista de Investigación Social, Año VIII(12), 9-38.

Medeiros, M. y Noël, A. (2014). The forgotten side of partisanship: Negative party identification in four Anglo-American democracies. Comparative Political Studies, 47(7), 10221046. DOI: https://doi.org/10.1177/0010414013488560

Meléndez, C. (2019). "Cualquiera menos tú». Identidades Negativas: los casos del antiaprismo y del antifujismorismo. En El mal menor: vínculos políticos en el Perú posterior al colapso del sistema de partidos (pp. 103-156). Lima: Instituto de Estudios Peruanos.

Murillo, M. V. (2017). La democracia argentina, entre vaivenes e incrementalismo. Revista SAAP: Sociedad Argentina de Análisis Político, 11(2), 203-211.

Murillo, M. V., Oliveros, V. y Vaishnav, M. (2011). Economic constraints and presidential agency. En S. Levistky \& K. M. Roberts (Eds.), The resurgence of the Latin American left (pp. 52-70). The Johns Hopkins University Press Baltimore.

Murillo, M. V., Rubio, J. y Mangonnet, J. (2016). Argentina: el protagonismo de los votantes y la alternancia electoral. Revista de ciencia política (Santiago), 36(1), 3-26. DOI: https://doi.org/10.4067/S0718090X2016000100001

Murillo, M. V. y Zarazaga, R. (2020). Argentina: Peronism Returns. Journal of Democracy, 31(2), 125136. DOI: https://doi.org/10.1353/jod.2020.0026

Natanson, J. (2019). Argentina: elecciones en tiempos de grieta. Nueva sociedad, (281), 4-11.

Niedzwiecki, S. y Pribble, J. (2017). Social policies and center-right governments in Argentina and Chile. Latin American Politics and Society, 59(3), 7297. DOI: https://doi.org/10.1017/S1531426X00010281 
Ostiguy, P. (1997). Peronismo y antiperonismo: Bases socioculturales de la identidad política en la Argentina. Revista de Ciencias Sociales, (6), 133-215.

Pikielny, A. (2019, mayo 26). Aníbal Pérez-Liñán. "La polarización extrema despolitiza a la sociedad". La Nación. Recuperado de https://www.lanacion.com. ar/opinion/biografiaanibal-perez-linan-la-polarizacionextrema-despolitiza-a-la-sociedad-nid2251023

Ratto, M. C. (2020). Otra vez la economía. La influencia de la agenda económica en las elecciones 2019. Más poder local, (40), 38-45.

Rosso, F. (2019). La enigmática supervivencia política de Mauricio Macri. Nueva Sociedad, (279), 4-12.

Singer, M. M. y Carlin, R. E. (2013). Context counts: The election cycle, development, and the nature of economic voting. The Journal of Politics, 75(3), 730-742. DOI: $\underline{\text { https://doi.org/10.1017/ }}$ $\underline{\text { S0022381613000467 }}$

The John Hopkins University. (2020). Coronavirus Resource Center. Recuperado 25 de mayo de 2020, de https://coronavirus.jhu.edu/map.html

Torre, J. C. (2017). Los huérfanos de la política de partidos revisited. Revista SAAP: Sociedad Argentina de Análisis Político, 11(2), 241-249.

Vommaro, G. y Gené, M. (2017). Argentina: el año de Cambiemos. Revista de ciencia política (Santiago), 37(2), 231-254. DOI: https://doi.org/10.4067/s0718090×2017000200231

Zarazaga, R. (2014). Brokers beyond clientelism: A new perspective through the Argentine case. Latin American Politics and Society, 56(3), 23-45. DOI: https://doi.org/10.1111/j.1548-2456.2014.00238.x

Zarazaga, R. (2018). "Todos unidos triunfaremos...": Nuevas dificultades para la unidad electoral peronista. Revista SAAP: Sociedad Argentina de Análisis Político, 13(1), 13-42. DOI: https:// doi.org/10.46468/18531970.13.1.A1

\section{Anexos.}

Gráfico 1. El problema más importante en Argentina

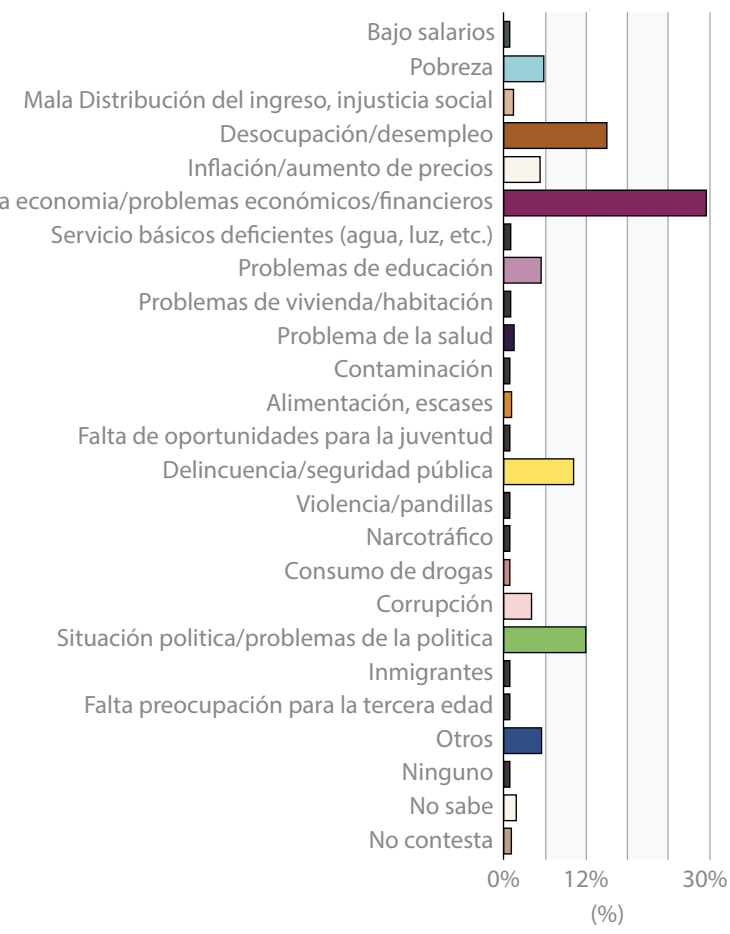

Fuente: Latinobarómetro (2018). 